\title{
Study on the Urban Rail Transit Sleeper Spacing Considering Vehicle System
}

\author{
Yu Zou' ${ }^{1}$, Yongpeng Wen ${ }^{1,}$ a and Qian Sun ${ }^{1}$ \\ 1 School of Urban Railway Transportation, Shanghai University of Engineering Science, 333 Long Teng Road, Shanghai 201620, China
}

\begin{abstract}
To design the optimal sleeper spacing of the track and reduce the vertical vibration of the rail, the influence of the sleeper spacing on the rail vibration is analysed in the vehicle-track vertical coupling model. By comparing the effects of vehicle speed and load on the vibration response of rails under different sleeper spacings, the importance of vehicle system is pointed out. According to the power spectrum density of the vertical rail displacement, the optimal sleeper spacing under the specific line is proposed, and verified via the vibration decay rate. The results show that the sleeper spacing directly affects the first-order Pinned-pinned vibration of the rail, and the effects of the speed and the load on the vibration response are different. In the low-speed section, the impact of the sleeper spacing on the vibration response is smaller, and the larger spacing can be appropriately selected to reduce the number of sleeper to save costs. However, in the high-speed section, the impact is larger, and the speed and the load should be comprehensively considered to select the optimal sleeper spacing.
\end{abstract}

\section{Introduction}

With the development of urban rail transit lines in China, the vibration and noise problems caused by the operation of rail trains are also becoming more and more serious. In the track design process, the force of the rail at the sleeper support is directly related to the distance between the sleepers, and the magnitude of the force affects the vibration of the rail. Therefore, the study of sleeper spacing has received extensive attention from scholars [14].

In recent years, domestic and foreign scholars have done a lot of research on the issues related to sleeper spacing[2-6]. Wu T X et al. regarded the sleeper spacing and the track bed stiffness as random variables, and analysed their effects on the orbital vibration by numerical simulation. The results show that the dynamic compliance and decay rate of the rail in a certain area are not fixed due to the variation of the sleeper spacing and the stiffness of the track bed [2]. Jin X S et al. used numerical methods to study the influence of sleeper spacing on the initiation and development of tangential orbital wave grinding. In the semi-vehicle track model, the easy-excitation resonance frequency of the wheelset and the track at different speeds is analysed in detail, and the influence of the discrete sleeper support on the normal load of the wheel-track is analysed at different speeds [3]. Batjargal $\mathrm{S}$ et al. studied the theory of optimizing sleeper spacing in the Timoshenko beam orbit model. The results show that the optimization of the sleeper spacing is beneficial to reduce the vibration response of the rail in the high frequency band, and the effectiveness of the vibration reduction method is verified by harmonic response analysis [4]. Šestáková J et al. considered that the relevant design and geometric parameters of the track include track alignment, gauge, superelevation and distortion, and evaluated the characteristics of different orbital structures through experiments [5]. Gao L et al. established a finite element model of slab ballastless track vibration to study the factors affecting the Pinned-pinned resonance of the rail. The results show that the change of the sleeper spacing will cause the Pinned-pinned resonance characteristics of the rail to change, which is a sensitive parameter [6]. In summary, most of the above studies are in the track model, and the influence of the vehicle system is rarely considered. Even considering the vehicle, the influence of the sleeper spacing on the rail vibration is studied only under the fixed vehicle speed. Due to the variable speed and passenger capacity of urban rail transit, the different working conditions of vehicles in different sections have great differences, and the operation state of a certain vehicle cannot accurately analyse the role of the sleeper spacing.

In the paper, a vehicle-track coupling model is established. According to the different working conditions of the vehicle system, the influence of the sleeper spacing on the vertical vibration response of the rail is studied, and the importance of vehicle system to rail research is pointed out. The effects of speed and load on the vertical vibration of rails are compared, then the recommendations for the optimal sleeper spacing are proposed for the lines with different characteristics of urban rail transit.

\footnotetext{
a Corresponding author: yp_wen@163.com
} 


\section{Vehicle-track coupling Model}

Figure 1 shows the vertical dynamics model of the vehicle-track coupled system. The vehicle model is type $A$ and the rail model is UIC60. The vehicle system consists of a carbody, two bogie and four wheelsets, all of which are considered rigid bodies.

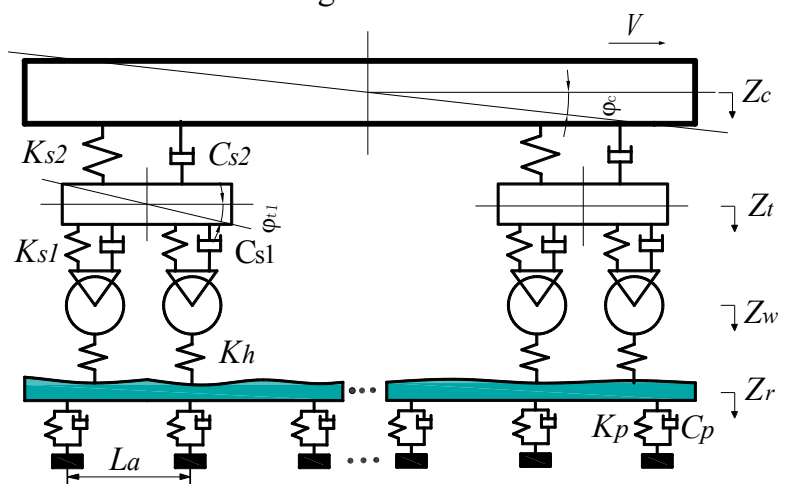

Figure 1. Vehicle-track coupling system vertical dynamics model.

Both the carbody and the bogie have two degrees of freedom of bounce and pitch. $Z_{c}$ and $\varphi_{c}$ are used to indicate the vertical displacement and the pitch angle of the carbody, and $Z_{t}, \varphi_{t}$ are used as the vertical displacement and the pitch angle of the bogie; each wheelset has a degree of freedom in bounce, and $Z_{w}$ is used to indicate the vertical displacement of the wheelset.
The running speed of the vehicle is $V$, and the running direction is positive to the right. The track section is a 50 $\mathrm{m}$ long pillow-buried ballastless track. The rail is regarded as a simply supported Euler beam, and its vertical displacement is indicated by $Z_{r}$. In order to broaden the applicable frequency range of the Euler beam model, the sectional inertia of the rail section is taken as $75 \%$ of the value in the table [7]. The remaining parameters are shown in Table 1.

According to the bending dynamics of the beam and the stress of the rail, the vibration differential equation of the rail is established [8]:

$$
\begin{aligned}
& E_{r} I_{r} \frac{\partial^{4} Z_{r}(x, t)}{\partial x^{4}}+M_{r} \frac{\partial^{2} Z_{r}(x, t)}{\partial t^{2}} \\
& +\sum_{i=1}^{N_{r}} \delta\left(x-x_{i}\right) F_{r i}(t)=\sum_{j=1}^{4} \delta\left(x-x_{w j}\right) F_{w j}(t)
\end{aligned}
$$

Where, $N_{r}$ is the total number of fastener nodes on the rail sleeper, that is, the number of sleepers, $x_{i}$ is the coordinate value of the $i$-th fastener node on the rail. And $F_{r i}$ is the fastener fulcrum force, and $x_{w j}$ is the coordinate value of the $j$-axis wheelset. Then $F_{w j}$ is the force of the wheel and rail action.

Table 1. Parameters of vehicle-rail coupling model for a city rail vehicle.

\begin{tabular}{lll}
\hline \multicolumn{1}{c}{ Meaning } & Parameter & Value \\
\hline mass of the carbody & $M_{c}$ & $3.4 \times 10^{4} \mathrm{~kg}$ \\
mass of the bogie & $M_{t}$ & $2.8 \times 10^{3} \mathrm{~kg}$ \\
mass of the wheelset & $M_{w}$ & $1.119 \times 10^{3} \mathrm{~kg}$ \\
mass of per unit length of the rail & $M_{r}$ & $60.64 \mathrm{~kg} \cdot \mathrm{m}^{-1}$ \\
\hline moment of inertia for carbody pitch & $J_{c}$ & $1.686 \times 10^{6} \mathrm{~kg} \cdot \mathrm{m}^{2}$ \\
moment of the bogie pitch & $J_{t}$ & $1.42 \times 10^{3} \mathrm{~kg} \cdot \mathrm{m}^{2}$ \\
Elastic modulus of the rail & $E_{r}$ & $2.059 \times 10^{11} \mathrm{~N} \cdot \mathrm{m}^{-2}$ \\
Sectional inertia of the rail & $I_{r}$ & $3.217 \times 10^{-5} \mathrm{~m}^{4}$ \\
\hline vertical equivalent stiffness of the primary suspension & $K_{s 1}$ & $3.68 \times 10^{6} \mathrm{~N} \cdot \mathrm{m}^{-1}$ \\
vertical equivalent stiffness of the secondary suspension & $K_{s 2}$ & $1.98 \times 10^{6} \mathrm{~N} \cdot \mathrm{m}^{-1}$ \\
vertical stiffness of the fastener & $K_{p}$ & $5 \times 10^{7} \mathrm{~N} \cdot \mathrm{m}^{-1}$ \\
vertical damping of the primary suspension & $C_{S 1}$ & $6.6 \times 10^{4} \mathrm{~N} \cdot \mathrm{s} \cdot \mathrm{m}^{-1}$ \\
vertical damping of the secondary suspension & $C_{s 2}$ & $6.4 \times 10^{4} \mathrm{~N} \cdot \mathrm{s} \cdot \mathrm{m}^{-1}$ \\
vertical damping of the fastener & $C_{p}$ & $7.5 \times 10^{4} \mathrm{~N} \cdot \mathrm{s} \cdot \mathrm{m}^{-1}$ \\
\hline$--------{ }^{-1}$ & $L_{b}$ & $7.85 \mathrm{~m}$ \\
half the length between the truck centers & $L_{w}$ & $1.25 \mathrm{~m}$ \\
half the wheelbase & $L_{c}$ & $21.88 \mathrm{~m}$ \\
length of the carbody & $L_{r}$ & $50 \mathrm{~m}$ \\
\hline length of the rail & & \\
\hline
\end{tabular}


Generally, the total length of the rail and the number of sleepers are used to indicate the sleeper spacing:

$$
L_{a}=L r / N r
$$

Where, $L_{a}$ is the sleeper spacing.

Combining the vehicle with orbital dynamics equation and perform a Fourier transform on it:

$$
\left(-\omega^{2} \boldsymbol{M}+j \omega \boldsymbol{C}+\boldsymbol{K}\right) \boldsymbol{Z}(\omega)=\boldsymbol{K}_{f} \boldsymbol{q}(\boldsymbol{\omega})
$$

Where, $\boldsymbol{M}, \boldsymbol{C}$, and $\boldsymbol{K}$ are the mass, damping, and stiffness matrices of the system, $\boldsymbol{Z}(\boldsymbol{\omega})$ is the output matrix of the system, $\boldsymbol{K}_{\boldsymbol{f}}$ is the system transformation matrix, and $\boldsymbol{q}(\omega)$ is the input matrix of each wheelset of the vehicle.

The vehicle system and the track system are coupled by wheel-rail contact force, and it is a nonlinear force. In order to facilitate the calculation and make the wheel-rail contact force a linear force, it can be linearized by the wheel-rail contact stiffness, which is specifically expressed as:

$$
K_{h}=\frac{3}{2} \frac{1}{G} P^{\frac{1}{3}}
$$

Where, $G$ is the wheel-rail contact constant, and $P$ is the wheel-rail static force.

The wheel-rail static force is the total weight exerted on the rail by the various components of the vehicle system, it can be expressed as:

$$
P=9.8\left(M_{c}+2 M_{t}+4 M_{w}\right)
$$

The vehicle system runs on the track at the speed $V$, and the track irregularity excitation $q_{1}(\omega)$ is input to the rail, and the displacement $Z_{i}$ is output, which is the frequency response characteristic function, and it can be expressed as:

$$
\begin{aligned}
& H(\omega)_{Z_{i}-q_{1}}+\omega^{2} q_{1}(\omega)^{-1}\left(-\omega^{2} \boldsymbol{M}+j \omega \boldsymbol{C}+\boldsymbol{K}\right)^{-1} \boldsymbol{Q} \boldsymbol{K}_{\boldsymbol{f}} \\
& +\omega^{2}\left[\begin{array}{lll}
h_{1}(\omega) & \mathrm{L} & h_{10+M}(\omega)
\end{array}\right]^{T}=0
\end{aligned}
$$

Where, $\quad h_{11}(w) \mathrm{L} h_{10+M}(w)$ is the displacement frequency response function of each mode of the rail.

When the power spectrum density (PSD) of the track irregularity excitation is input, the output rail vertical displacement PSD can be expressed as:

$$
G_{Z_{i}}(\omega)=|H(\omega)|_{Z_{i}-q_{1}}^{2} G_{q_{1}}(\omega)
$$

Where, $G_{q_{1}}(\omega)$ is the displacement PSD of the track irregularity excitation.

\section{Physical meaning of the sleeper spacing}

In the urban rail transit line laying structure, the rail is fixed by the fastener device above the equally spaced discrete sleepers. This form of installation causes the rail to be excited to produce a longitudinal mechanical wave with its standing wave node just at the support of the sleeper, which is the Pinned-pinned vibration of the rail. According to the relevant measured results, the rail radiated noise is the main component of the wheel-rail rolling noise in the frequency range of 500-1500 Hz. The noise peak caused by the first-order Pinned-pinned vibration of the rail is within this frequency range [9]. The first-order Pinned-pinned vibration frequency $f_{p p}$ is related to the rail section type, the rail mass and the sleeper spacing [10], which can be expressed as:

$$
f_{p p}=\frac{\pi}{2 L_{a}^{2}}\left(\frac{E_{r} I_{r}}{M_{r}}\right)^{1 / 2}
$$

It can be known from equation (8) that the value of the sleeper spacing directly affects the peak frequency of the Pinned-pinned vibration of the rail. The larger the distance between the sleepers is, the smaller the firstorder Pinned-pinned vibration frequency of the rail.

The distance between railway sleepers in China is generally $0.6 \mathrm{~m}$, and the distance between curved sections with a radius less than $800 \mathrm{~m}$ is generally $0.625 \mathrm{~m}$. The distance between the sleepers of foreign urban rail transit systems is generally not less than $0.7 \mathrm{~m}$, and the curve section is to ensure the smoothness of the rails from 0.7 $\mathrm{m}$ to $0.9 \mathrm{~m}$.

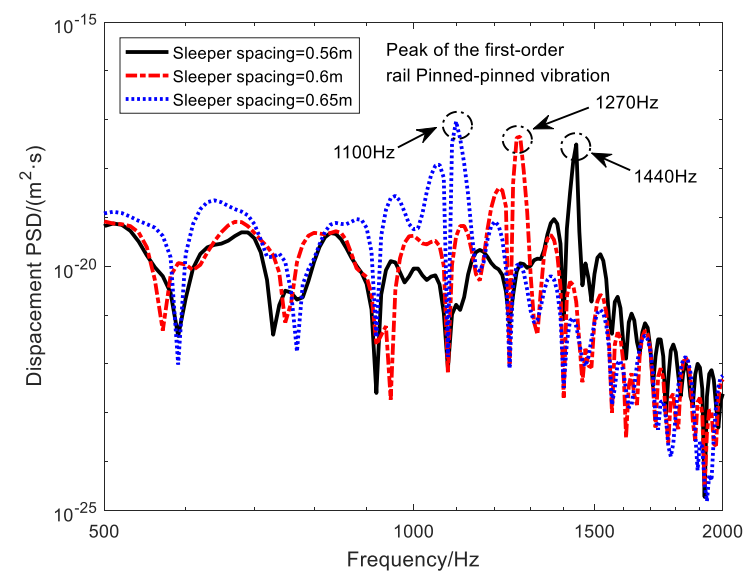

Figure 2. Vertical displacement power spectrum of the midpoint of a $50 \mathrm{~m}$ rail.

The paper uses a model of a $50 \mathrm{~m}$ long linear orbit. Select a car to move on the track, compare the vertical displacement PSD of the midpoint of the three different sleeper spacings under $80 \mathrm{~km} / \mathrm{h}$ speed and no-load conditions, as shown in Figure 2. It can be seen from Fig. 2 that in the frequency range of $500-2000 \mathrm{~Hz}$, the vertical vibration response of the rail increases first and then decreases, and the vibration peak is formed at the peak of the first-order Pinned-pinned vibration. When the sleeper spacing is increased from $0.56 \mathrm{~m}$ to $0.65 \mathrm{~m}$, the first- 
order Pinned-pinned vibration peak frequency of the rail is reduced from $1440 \mathrm{~Hz}$ to $1100 \mathrm{~Hz}$, and the vibration peak is gradually increased. The change of the value of the sleeper spacing will not only change the first-order Pinned-pinned vibration peak frequency of the rail, but also affect the vertical vibration amplitude of the rail. It is a sensitive parameter affecting the rail vibration in the track structure. Therefore, in the process of laying urban rail transit sleepers, various designs that emphasize the optimal sleeper spacing should be considered.

Figure 2 is an analysis of the sleeper spacing with fixed load and speed. In the following, the effects of speed and load on the vertical vibration of the rail will be further studied in combination with the frequent changes of urban rail transit speed and the large difference in passenger capacity between different lines.

\section{Influence of vehicle system on vertical vibration of rail}

\subsection{Influence of speed}

Due to the frequent changes in urban rail transit passenger flow and the length of station spacing, and the frequent start, acceleration and braking of vehicles [11], the running speed of each section is quite different. Under no-load condition, the traversal is performed in the speed range of $0 \sim 80 \mathrm{~km} / \mathrm{h}$, and the peak of the vertical displacement PSD of the midpoint of the rail is compared with the three kinds of sleeper spacing, as shown in Fig. 3.

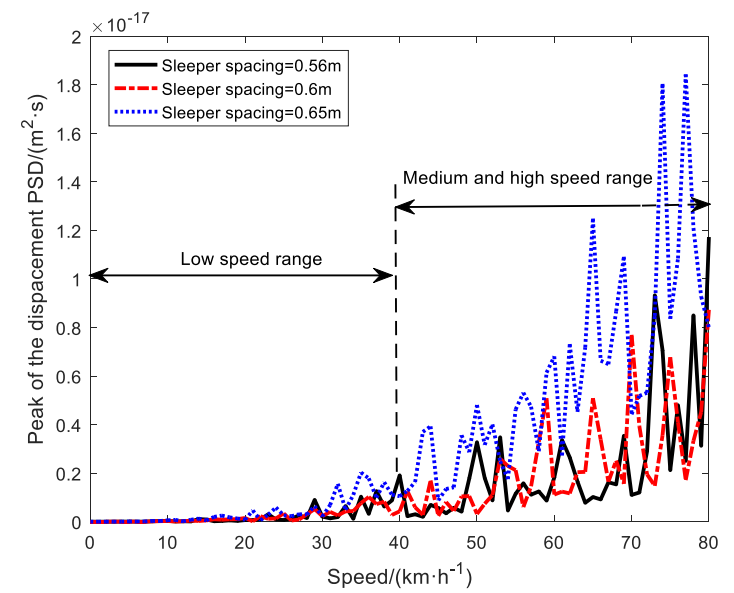

Figure 3. Effect of speed on rail vibration under different sleeper spacing.

Fig. 3 presents that under the three sleeper spacings, the vertical vibration of the rails increases with the increase of the speed, that is, the vibration response of the rails in the high speed range is basically greater than the response in the low speed range. This is because the increase in speed increases the force of action between the wheel and rail, resulting in an increase in rail vibration [12-14]. In addition, it is worth noting that in the low speed range, the change in the value of the sleeper spacing has less effect on the vertical vibration response of the rail during the same speed vehicle operation. In the high-speed range, when the vehicle of the same speed travels on the line with different sleeper spacing, the vertical vibration response of the rail has a big difference. When the sleeper spacing is $0.65 \mathrm{~m}$, the peak curve of the vertical displacement power spectrum of the rail is the highest. Therefore, under different speeds (especially high-speed intervals), choosing the most suitable sleeper spacing is beneficial to control the vertical vibration of the rail and thus control the radiation noise between the wheel and rail.

\subsection{Influence of load}

The large change in passenger capacity is another significant feature of urban rail transit [11]. Passenger traffic is often large in the downtown area, and vehicles are fully loaded or even overloaded most of the time, while in the suburbs, urban rail transit passenger traffic is generally maintained at medium and below conditions. The difference in passenger flow results in different vehicle load conditions, and the impact of different sleeper spacing lines on the vertical vibration of the rails is also different.

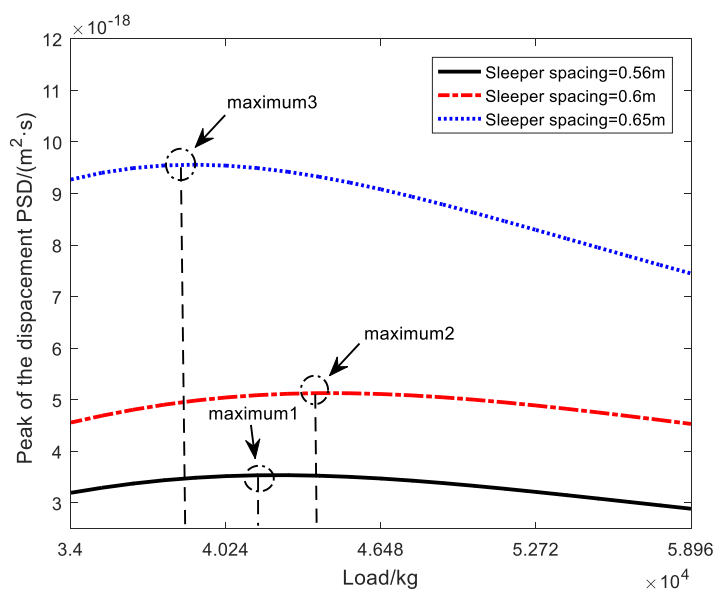

Figure 4. Effect of load on rail vibration under different sleeper spacing.

Figure 4 shows the variation curve of the vertical displacement PSD of the rail from no load to overload during different distances of the sleeper at $80 \mathrm{~km} / \mathrm{h}$. It can be seen from Fig. 4 that during the change of the vehicle from no load to overload, the peak value of the vertical displacement PSD of the rail shows a trend of increasing first and then decreasing. However, the maximum curve corresponding to different sleeper spacings appears under different vehicle load values. Moreover, in the process of changing the distance between the sleepers from $0.56 \mathrm{~m}$ to $0.65 \mathrm{~m}$, the larger the spacing value, the more severe the vertical response of the rail. That is to say, when the vehicle is running on the line with different sleeper spacing under the same load condition, there is a certain difference in the vibration response of the rail. Therefore, it is necessary to design the most suitable sleeper spacing for a specific track line for different load conditions of the vehicle, so as to achieve the purpose of controlling the vertical vibration of the rail and the radiation noise between the wheel and rail. 


\section{Designing of the optimal sleeper spacing}

In view of the diversity of vehicle speed and load capacity, the design of the optimal sleeper spacing is studied from the perspective of speed and load.

The paper takes the peak of the vertical displacement power spectral density of the rail as the index to find the

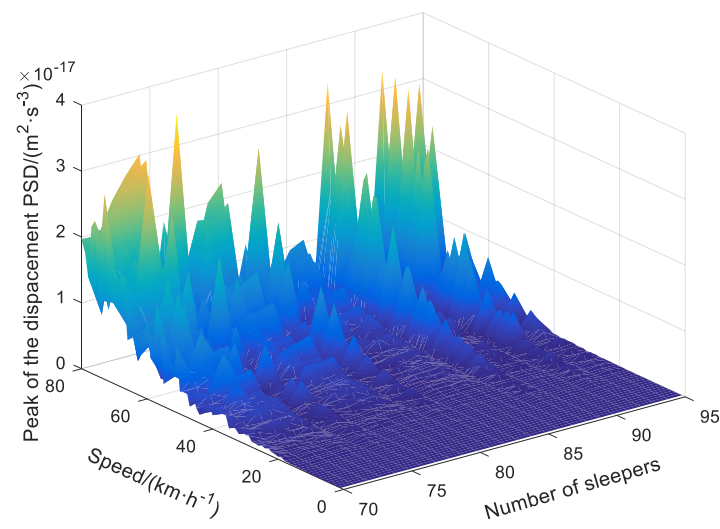

(a). Aw0 working condition.

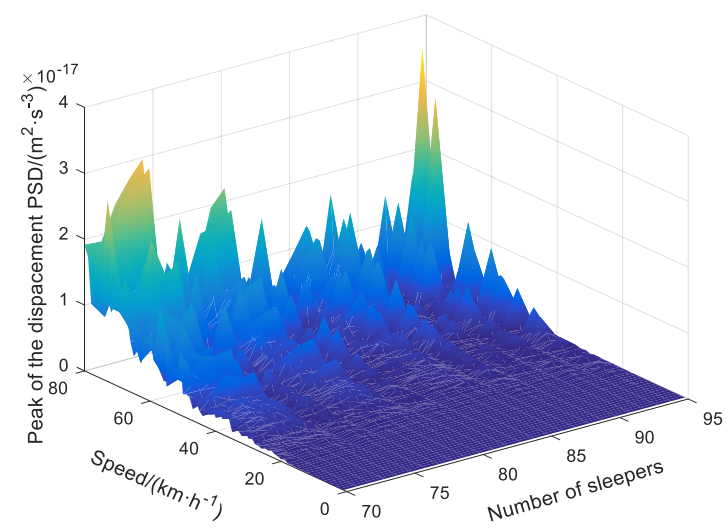

(c). Aw2 working condition. optimal sleeper spacing. According to the common sleeper spacing in China, the range of spacing is determined to be between $0.5 \mathrm{~m}$ and $0.7 \mathrm{~m}$. In the model, a length of $50 \mathrm{~m}$ is used, that is, the number of rails is about 70 to 95 . Under the four typical load conditions (no load, heavy load, full load and overload), the traversal selection of the $50 \mathrm{~m}$ rail sleeper number in the range of $0 \sim 80 \mathrm{~km} / \mathrm{h}$ is shown in Fig. 5 .

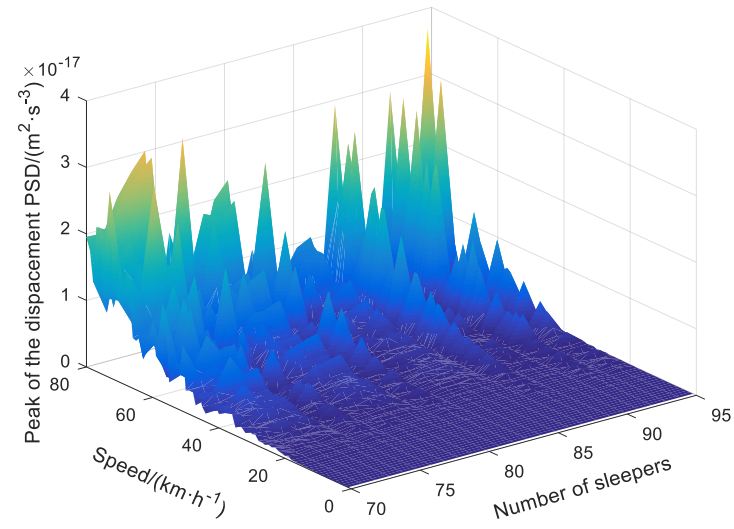

(b). Aw1 working condition.

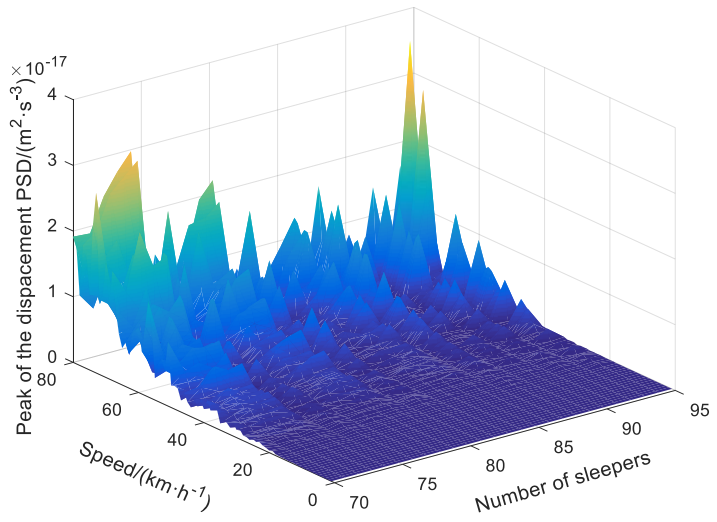

(d). Aw3 working condition.

Figure 5. Vertical vibration response of rail under four load conditions

Referring to Fig. 5 (a), (b), (c), (d), it can be seen that the rail vertical vibration response is small in the low speed section below $40 \mathrm{~km} / \mathrm{h}$ regardless of the load condition. Moreover, the influence of the change of the sleeper spacing on the vertical vibration of the rail is also less obvious; In the speed range of $40 \sim 80 \mathrm{~km} / \mathrm{h}$, the vertical response of the rail gradually increases with the increase of the speed of the same sleeper spacing, which corresponds to Figure 2. In the different load conditions of (a), (b), (c), (d), the magnitude of the ordinate axis corresponding to the number of the same sleeper is also different.

In order to obtain the regularity of the vertical vibration response amplitude of the rail under the four load conditions, the number of sleepers is the abscissa, and the maximum value of the peak of the rail displacement power spectral density corresponding to the number of each sleeper is taken as the ordinate, and four load cases are obtained. The different curves are shown in Figure 6.
It can be seen from Fig. 6 that the maximum value of the peak of the displacement PSD of the rail corresponding to the number of different sleepers forms a curve with multiple peaks and valleys. The valley value corresponds to the optimal sleeper spacing that minimizes the vertical vibration response of the rail under this condition, and the peak value is the opposite. The curves under different load conditions do not overlap completely, but the values on the curve are peak or valley just when the same number of sleepers is used. As indicated in the figure, when the number of sleepers is $75,83,87,89,91$ and 93, that is, when the sleeper spacing is $0.67 \mathrm{~m}, 0.6 \mathrm{~m}$, $0.57 \mathrm{~m}, 0.56 \mathrm{~m}, 0.55 \mathrm{~m}$ and $0.54 \mathrm{~m}$, the peak of the vertical displacement PSD of the rail is the smallest, that is, the vertical vibration response is the lowest. 


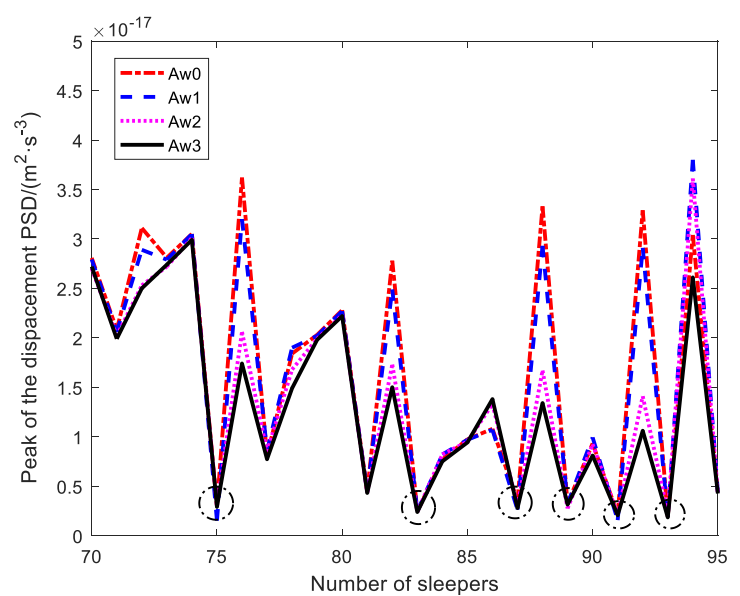

Figure 6. Peak curve of rail displacement spectrum with different number of sleepers.

As can be seen from Fig. 5 and Fig. 6, in the lowspeed straight line segment (such as the yard line and the maintenance line), the change of the line sleeper spacing has little effect on the vertical vibration response of the rail regardless of the load capacity. Considering economic factors, it is possible to appropriately select a larger sleeper spacing and reduce the number of laying sleepers to save costs. In the high-speed section (such as the suburban line and the larger station spacing), the change of the sleeper spacing has a greater impact on the vertical vibration response of the rail. Considering the factors of speed and load, combined with the actual topography, it is recommended to select the optimal sleeper spacing at $0.67 \mathrm{~m}, 0.6 \mathrm{~m}, 0.57 \mathrm{~m}, 0.56 \mathrm{~m}, 0.55 \mathrm{~m}$ and $0.54 \mathrm{~m}$.

\section{Verification}

At present, the vibration decay rate is usually used in the study of rail vibration to reflect the ability of vibration to decay along the rail [15-16]. In a frequency range, the greater the vibration decay rate value, the smaller the vibration response of the rail. The paper uses the vibration decay rate to verify the optimal sleeper spacing value.

The vibration decay rate of the rail can be solved by the displacement response, which can be expressed as:

$$
r=\frac{20 \lg \left|Z_{r}\left(X_{1}\right) / Z_{r}\left(X_{2}\right)\right|}{\Delta X}
$$

Where, $Z_{r}\left(X_{1}\right)$ is the vertical displacement of the rail at the excitation point, $Z_{r}\left(X_{2}\right)$ is the vertical displacement of the rail at the inspection point, and $\Delta X$ is the distance between $X_{1}$ and $X_{2}$.

According to Fig. 6, when the number of sleepers for the $50 \mathrm{~m}$ rail is 88 , that is, the distance between the sleepers is $0.57 \mathrm{~m}$, and the ordinate is the peak value, indicating that the rail has the largest vertical response when the sleeper is spaced. When the number of sleepers for the $50 \mathrm{~m}$ rail is 75 , that is, the distance between the sleepers is $0.67 \mathrm{~m}$, the ordinate is the valley value, indicating that the vertical response of the rail is the smallest. Select the two types of sleeper spacing and compare the root mean square value of the vibration decay rate of the rail in the high speed range of 40-80 $\mathrm{km} / \mathrm{h}$, as shown in Fig. 7.

It can be seen from Fig. 7 that in the high speed range of $40-80 \mathrm{~km} / \mathrm{h}$, the root mean square value of the vibration decay rate of the rail when the sleeper spacing is $0.67 \mathrm{~m}$ is significantly larger than the value of the vibration attenuation rate when the sleeper spacing is $0.57 \mathrm{~m}$. That is to say, compared with 88 sleepers, laying 91 sleepers in the $50 \mathrm{~m}$ linear rail range makes the rail vibration response smaller, which corresponds to the content of Fig. 6. Therefore, in the vehicle-track coupling model, the speed and load factor of the vehicle system should be fully considered, and the optimal sleeper spacing is selected according to the characteristics of the line, which has obvious effects on reducing the vibration of the rail.

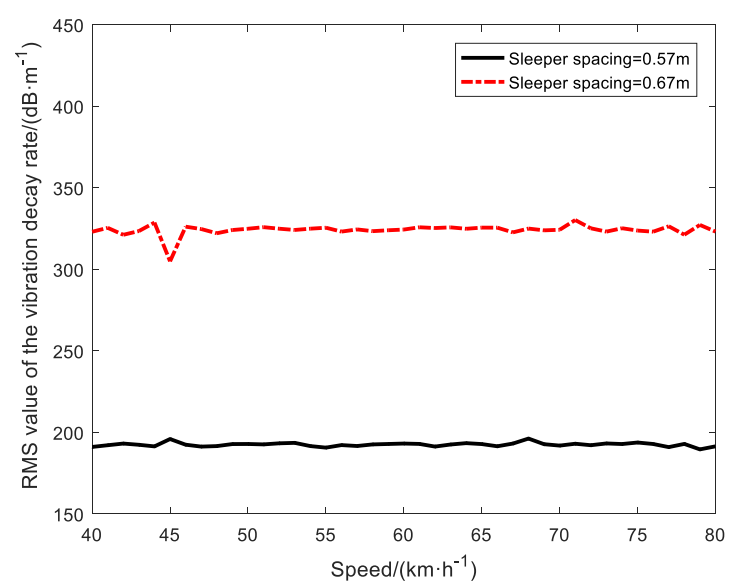

Figure 7. Root mean square value of vibration decay rate of rail under two types of sleeper spacing.

\section{Conclusions}

The sleeper spacing directly affects the value of the firstorder Pinned-pinned vibration peak frequency of the rail. And under different sleeper spacings, the influence of the vehicle speed and the load on the vibration response of the rail is different. Therefore, when designing the sleeper spacing for the line, the role of the vehicle system should be considered comprehensively.

Under different load conditions, the vertical vibration response amplitude of the rail is different when the same sleeper spacing is used. However, the law of vibration response changes with the spacing is basically similar. The extreme values of the vibration response of the rail under different load conditions are consistent with the same number of sleepers.

In the low-speed section, regardless of the load conditions, the change of the sleeper spacing has little effect on the vertical vibration response of the rail. Considering economic factors, it is possible to appropriately select a larger spacing and reduce the number of laying sleepers to save costs. In the high-speed section, the change of the sleeper spacing has a greater influence on the vibration response of the rail. Considering the effects of speed and load on the coupling 
system, it is recommended to choose the optimum sleeper spacing between $0.67 \mathrm{~m}, 0.6 \mathrm{~m}, 0.57 \mathrm{~m}, 0.56 \mathrm{~m}, 0.55 \mathrm{~m}$ and $0.54 \mathrm{~m}$.

\section{Acknowledgements}

This research was partially supported by the National Natural Science Foundation of China (Grant No. 11472176) and the Natural Science Foundation of Shanghai (Grant No. 15ZR1419200).

\section{References}

1. Zhang P, Wang A B, Wang Z Q, Xu N and Zhang Z Y 2016 Influence of track parameters on rail PinnedPinned vibration. Urban. Mass. Transit. 19(12) 72$76+82$

2. Wu T X, Thompson D J 2000 The influence of random sleeper spacing and ballast stiffness on the vibration behaviour of railway track. Acta. Acust. United. Ac. 86(2) 313-321

3. Jin X S, Xiao X B, Wen Z F and Zhong R Z 2008 Effect of sleeper pitch on rail corrugation at a tangent track in vehicle hunting. Wear. 265(9) 1163-1175

4. Batjargal S, Abe K, Koro K 2012 Sleeper spacing optimization for vibration reduction in rails. $J$. Comput. Struct. Eng. Inst. Korea. 25(6) 569-577

5. Šestáková J, Mečár M 2015 Evaluation of track design and track geometry of the track with unconventional structure of railway superstructure. Procedia. Eng. 111 709-716

6. Gao L, Cui R X, Hou B W and Xiao H 2018 Sensitivity analasis of influence parameters on resonance characteristics of ballasted track rail. $J$. Hunan Univ: Nat. Sci. Ed 45(03) 115-121
7. Zhao Y, Xiao X B, Han J, Zhao G T and Jin X S 2013 Vertical characteristic and its parameter effect of rail vibration absorber used in high-speed ballasted track. Chin. J. Mech. Eng. 49(16) 17-25

8. Zhai W M, Wang K Y, Cai C B 2009 Fundamentals of vehicle-track coupled dynamics. Vehicle Syst Dyn. 47(11) 1349-1376

9. Thompson D J, Jones C J C 2000 A review of the modelling of wheel/rail noise generation. J. Sound. Vib. 231(3) 519-536

10. Sun F Q, Gu A J, Liu W N 2013 A Study on vibration and transmission characteristics of long solid models under different frequencies. J. Railway Soc. 35(2) 81-86

11. Wen Y P, Li Q, Shang H L and Xu X J 2016 Study on the performance of dynamic vibration absorber for the carbody vibration considering the effects of vehicle-track coupling. J. Railway Soc. 35(21) 53-62

12. Nordborg A 1998 A Parametrically excited rail/wheel vibrations due to track-support irregularities. Acta. Acust. United. Ac. 84(5) 854-859

13. Connolly D P, Kouroussis G, Woodward P K, Alvescosta P, Verlinden O and Forde M C 2014 Field testing and analysis of high speed rail vibrations. Soil. Dyn. Earthq. Eng. 67 102-118

14. Sheng X, Li M, Jones C J C and Thompson D 2007 Using the Fourier-series approach to study interactions between moving wheels and a periodically supported rail. J. Sound. Vib. 303(3-5) 873-894

15. Wu T X 2008 On the railway track dynamics with rail vibration absorber for noise reduction.J. Sound. Vib. 309(3) 739-755

16. Liu H P, Wu T X, Li Z G 2009 Theoretical modeling and effectiveness study of rail vibration absorber for noise control. J. Sound. Vib. 323(3) 594-608 